\title{
Virtual Reality and its role in removing the barriers that turn cognitive impairments into intellectual disability
}

\author{
STANDEN $\mathrm{PJ}^{1}$ \\ BROWN DJ ${ }^{2}$ \\ ${ }^{1}$ Division of Rehabilitation \& Ageing, School of Community Health Sciences, \\ University of Nottingham, B Floor, Medical School, Queen's Medical Centre, \\ Nottingham NG7 2UH \\ p.standen@nottingham.ac.uk Telephone: +44 01158230233 \\ ${ }^{2}$ School of Computing \& Informatics, Nottingham Trent University, Clifton Campus, \\ Clifton Lane, Nottingham NG11 8NS \\ David.Brown@ntu.ac.uk
}

\begin{abstract}
Early expectations of the contribution that virtual reality (VR) could make to education far exceeded actual applications. This was largely due to the initial immaturity of the technology and a lack of evidence base on which to base design and utilisation. While the early developments in computer based learning largely concentrated on mainstream education, leaving those with special needs behind, the potential of VR as an educational tool was exploited for those with intellectual disabilities right from the start. This paper describes the empirical evidence that has contributed to the development of educational virtual reality for those with intellectual disabilities: studies on transfer of learning from the virtual to the real world; how teachers might support those using VR; the design of virtual environments and what input/control devices best facilitate use of desktop VR. Future developments and ethical issues are also considered.
\end{abstract}

Key words virtual reality, education, intellectual disability, cognitive impairments, tutor, user sensitive inclusive design

\section{Introduction}

Early expectations of the educational role of virtual reality (VR)were high:

"Education is forever seeking the Holy Grail: a tool which, at one and the same time, will make teachers' lives easier while presenting a better picture of the world to their pupils. Virtual Reality may well signal the end of the quest” (p3) ${ }^{1}$. This medium 
possessed characteristics that had the potential to transform the way students learnt. More significantly it had the potential to facilitate the learning of those with intellectual disabilities providing a route to the acquisition of knowledge and skills that could reduce the impact of their impairments. This new technology was being acclaimed in areas other than in education but the "expectation-to-delivery" ratio was imbalanced and "the real thing never quite lived up to expectations generated by initial media hype” $(\mathrm{p} 567)^{2}$. One of the reasons for the failure of virtual reality to deliver was that the state of technology at the time was not sufficiently advanced ${ }^{3}$. However, while the technology was developing, the evidence upon which to base its design was lacking. Off the peg software was not available and any educationalist who was keen to exploit this new tool was faced with an almost insurmountable task of commissioning a package in the absence of any guidelines for its design.

While the early developments in computer based learning largely concentrated on mainstream education, leaving those with special needs behind, the potential of virtual reality as an educational tool was exploited for those with intellectual disabilities right from the start. Our research team has been designing, building and evaluating educational virtual environments (VE) for people with intellectual disabilities since 1991. They were intended to facilitate the acquisition of skills to enable independent living (for example shopping, communication, route finding, travel training) or employment (for example health and safety in a workshop). We had hoped that virtual reality "may also be the precursor of a new strand of prosthesis technology which could provide 'intellectual amplification' that enables people with learning disabilities to transcend some of their individual mental limitations in exactly the same unremarkable way that some people today use spectacles to improve their vision”4. By ensuring efficient educational support was provided from the beginning of a student's school career, later intellectual disadvantage could be reduced thus "removing the barriers that turn cognitive impairments into intellectual disability" This paper describes some of the evidence we collected and some of the barriers we overcame in developing virtual reality as an educational tool for those with intellectual disabilities. 


\section{Why virtual Reality?}

A review of the potential of virtual reality for people with intellectual disabilities highlighted the characteristics that could prove advantageous ${ }^{5}$. Computer based learning, of which educational VR can be considered a sub-category, possessed qualities which should have led to its widespread use for this group of learners ${ }^{6,7,8}$. It enables learners to take charge of their own learning. Learners with intellectual disabilities would find stimulation through "enjoyable repetition” and a gradual increase in level of challenge: "Words like "handicapped” and "disabled" imply dependence and powerlessness: with computers, learners can be less dependent and more capable.” (p25) ${ }^{9}$. More recently it has been argued that enabling technology provides access for children to educational opportunities and life experiences, and facilitates engagement with knowledge and people: 'Speech, pictures, words, and animation can be combined in interactive ways to structure concepts to suit the level of understanding of learners and their interests.' (p1) ${ }^{10}$.

Interactive software encourages active involvement in learning and gives the user the experience of control over the learning process ${ }^{11}$. This is especially important for people with intellectual disabilities who have a tendency to behave passively ${ }^{12}$. The learner can work at their own pace ${ }^{9}$. They can make as many mistakes as they like without irritating others and the computer will not tire of the learner attempting the same task over and over again, nor get impatient because they are slow or engrossed in particular details ${ }^{13}$.

Virtual reality possesses three characteristics in addition to those shared with other forms of computer delivered education, which make them particularly appropriate for people with intellectual disabilities ${ }^{4}$. First, VE create the opportunity for people with intellectual disabilities to learn by making mistakes but without suffering the real, humiliating or dangerous consequences of their errors. People with intellectual disabilities are often denied real world experiences which might promote their further development because their carers are scared of the consequences of allowing them to do things on their own ${ }^{14}$. Accompanied visits to a real environment sufficient to learn a skill may be impossible to arrange. However, in the VE they can go where they like even if they have a mobility problem. Secondly, virtual worlds can be manipulated in 
ways the real world cannot be. In the real world the beginner can be provided with scaffolding in the form of add-ons like self-help manuals because the world cannot be changed. As she becomes familiar with elements of the task the scaffolding or training support is removed little by little until finally when the task is completely learned all scaffolding has been removed and the apprentice is on her own doing the job $^{15}$. In a virtual environment worlds can be constructed in any way the builder requires. A simple world can be constructed within which the task could be performed and as the user becomes more familiar with the task the world can become more complex. Features to which the learner needs to pay attention can be made more prominent ${ }^{16}$.

Thirdly, in virtual reality rules and abstract concepts can be conveyed without the use of language or other symbol systems. VE have their own "natural semantics"17: the qualities of objects can be discovered by direct interaction with them. They can thus be used to facilitate concept attainment through practical activity, by-passing the need for disembedded thinking ${ }^{18}$ which people with intellectual disabilities often find difficult to acquire and use. For example, instead of receiving the advice "if there is not enough water in the kettle, when you switch it on it will burn out", in a virtual kitchen, if programmed appropriately, the user who cannot understand such language can learn of the undesired consequences of switching on the electric kettle that contains insufficient water.

For people with intellectual disabilities, virtual reality is best experienced on a desktop system which employs an ordinary computer monitor with movement through the graphical environment achieved by the use of standard computer input devices such as keyboard, mouse, joystick, spaceball or touchscreen. In addition to being more easily available, one of the advantages of desktop systems is that the public nature of the display permits interactions between the learner and a tutor or a peer. Collaborative modes of learning and the role of instruction was emphasised by Vygotsky ${ }^{19}$. Bruner ${ }^{20}$ has also drawn attention to the social context out of which skills develop, highlighting the value of joint attention, shared activities and sensitive and responsive adults prepared to assign meaning to the learner's behaviour. 
The motivation for exploring the educational potential of virtual reality for students with intellectual disabilities was that policy and societal changes had created a need for new educational approaches and the characteristics described above made VR a prime candidate for meeting this need. Today, the majority of young people with intellectual disabilities no longer live in institutions but in the family home and, although their individual needs will differ, there is an expectation that when they leave full-time education they will achieve greater independence and greater inclusion in society ${ }^{21}$. The intention of current policy is to enable them to have as much choice and control as possible over their lives, be involved in their communities and to make a valued contribution to the world at work. However, in order to achieve these aims, there is a desperate need for education to equip them with the appropriate skills. Many adults with intellectual disabilities have missed out on this type of education while at school. For them too there is a need for courses which teach independent living and communication skills ${ }^{22}$ and this need has been reiterated by others ${ }^{23}$.

\section{Evaluating the effectiveness of VR as an aid to learning}

However, while virtual reality possess all these positive characteristics and is considered to provide safe arenas in which to acquire and practice skills, it is essential that skills learnt in this way transfer to the real world where they are required ${ }^{17}$. This has traditionally been a criticism of computer based teaching, particularly for people with intellectual disabilities whose performance is characterised as rigid, context dependent or as blind rule following ${ }^{24}$. Assessment of social skills training programmes shows that skills and knowledge learnt in training are unlikely to generalise beyond the teaching situation and even when they do they are rarely maintained for very long after training has ceased ${ }^{25,26}$. This failure to generalise has been attributed to both the design of the intervention ${ }^{27,28}$ and to the individual's perceived status within the group varying from setting to setting ${ }^{29}$. However, carefully designed studies have been successful in teaching skills which have generalised. Baty, Michie and Lindsay ${ }^{30}$ used role play to teach hospital based adults the skills involved in using a cafeteria and these transferred successfully to the real life situation. 
One of our first studies ${ }^{31}$ showed that not only was virtual reality effective in facilitating the acquisition of living skills but that these skills could transfer from the virtual to the real environment. Nineteen school students aged between 14 and 19 years with severe intellectual disabilities were taken to a supermarket to find four items on the shelves and take them to the checkout. Nine students then spent twiceweekly sessions carrying out a similar task in a virtual supermarket. The remaining students had the same number of sessions using other virtual environments. There was no difference between the two groups on their first visit to the real supermarket. Yet, on their return visit, those who had practised shopping in the virtual supermarket were significantly faster and more accurate than those who had not.

A later unpublished study assessed whether students starting at a special school could be helped to become familiar with their school by exploring a virtual model of it. Twenty two students aged between 7 and 19 years, who were just starting at a special school were divided into two groups. The first group experienced the usual school orientation course which consisted of seven sessions learning to find 16 markers in the real school. The second group spent these sessions finding the markers in the virtual school. On the eighth session, a teacher who did not know to which group the participants belonged tested all the pupils in the real school in their attempt to find a random selection of the markers. There was no difference between the two groups in the total time spent with the tutor over the seven training sessions so neither group had a differential advantage in the time they spent learning. The results of the study showed that the group who had learned on the computer had found significantly more markers by the end of the seventh session than had the group who had explored the real school. Thus, in the same amount of time, the virtual school had given the learners a greater opportunity to learn. In the eighth session, when they were tested by a different teacher, there was no difference between the two groups in the time taken to reach each marker. Neither was there any difference between them in the number and types of clues given once these figures were adjusted for the number of markers found. The fact that the computer group's performance was as good as that of the other group is evidence that the learning they experienced in the virtual school transferred to the real one. 


\section{How should teachers use virtual reality?}

The introduction of new technologies has frequently led to predictions that they will revolutionise education. Unsurprisingly, these claims are rarely realised. According to Light $^{32}$, many new technologies have been offered to education as panaceas in the past, only to provoke the reaction that 'the only successful piece of educational technology is the school bus'. Talking about computer use in general, Hope and Odor (cited in ${ }^{9}$ ) reported a growing suspicion that teachers would transfer old instructional techniques on to new media, and thus not fully exploit their potential. To avoid this happening with virtual reality, educators must take a proactive stance towards the growth of this important technology, rather than the reactive stance that has often been taken to educational technology developments in the past. 'If educators want virtual environments to meet learning needs, especially of those pupils who have unusual learning needs, they must play an active role in the development of applications, offering to developers their unique understanding of learning styles and good teaching practices.' (p2) ${ }^{33}$.

Words of caution expressed about the role of computers in education are just as salient when considering the contribution of VR to education. Rostron and Sewell ${ }^{34}$ see computers as just 'one more useful facility in the general remedial framework that is available' (p9), but advise that they are not there to replace human teachers, just to provide them with additional teaching aids. Early champions of the educational role of virtual reality extolled the advantage of the freedom to explore that it allowed ${ }^{35}$. However, there is growing criticism of the benefits of discovery learning ${ }^{36}$ and, although computers are highly motivating, caution has been expressed against the naïve belief that unguided interaction can effectively exploit their educational potential $^{37}$. There are two ways in which interaction can be guided in this form of learning: through the involvement of a human tutor or through including tutoring strategies in the software itself.

The inclusion of tutoring strategies in the software itself will be dealt with in a later section but what do we know about the role of the human tutor? Our early work on the transfer of learning from a virtual environment was carried out utilising desk top systems with a tutor sitting alongside the learner. However, in both schools and day 
centres staff are responsible for too many pupils to be able to give one-to-one tuition on a regular basis and when they are able to provide this function need guidance on effective strategies. Teachers need help and encouragement to build their confidence and skills in using computers and deserve proper training opportunities ${ }^{9}$. However, even for teachers currently qualified very few received the opportunity while training to consider how to use computers in their classroom. If trying to integrate the use of VR into special education, there would be no research on which to base the advice given to trainees.

In order to go some way to filling this gap we carried out a study to observe the teaching practices associated with the use of virtual reality in a school for children with intellectual disabilities ${ }^{38}$. Specifically, they looked at whether VE did enable learners to take charge of their own learning or whether teachers were using them in a more conventionally didactic manner. Eighteen school-aged pupils with severe intellectual disabilities and their teachers were videotaped while using an educational VE. Teachers' activity was coded into eight categories (for example, instruction, suggestion, pointing) and the pupils’ into three (for example, whether he or she moved in three-dimensional space) and measures of intra-rater reliability established. Teacher activity significantly decreased as the sessions progressed. However this drop was not as great as the increase in rates of pupil behaviour. This is because some behaviours (physical guidance and instruction) dropped at a faster rate, whereas others (suggestions) hardly changed. The interpretation of this could be that teachers are not just becoming fatigued but selectively dropping the more didactic and controlling behaviours. This can be explained with reference to the term 'scaffolding' 39 identified as one of the functions of teaching and described earlier.

Another function of the teacher or tutor ${ }^{39}$ is to maintain the learner's interest and motivation by drawing their attention to relevant features of the task, by interpreting discrepancies between the child's productions and correct solutions and by controlling the level of frustration experienced by the learner. This was represented by the categories of pointing and suggestion which decreased at a slower rate. These findings support the hopes expressed by some ${ }^{32}$ that the teacher-pupil interaction that occurs around computer based learning has the potential to reduce more didactic forms of teaching. 


\section{Design of environments}

Many questions arose about how our educational VE should be designed. What was the optimum degree of detail? Obviously sufficient detail was required to make the environment recognisable as say a cafe. However, too much detail may prevent the learner from recognising the salient features of the environment necessary to successfully carry out a task within it. What features of a real environment, for example a supermarket, needed to be represented in the virtual version to promote transfer to the variety of supermarkets that existed in the real world? In the absence of any existing design guidelines specifically developed for the implementation of VE for use by people with intellectual disabilities, we recently carried out a small scale usability review of existing VE at a local school for students with intellectual disabilities to determine commonly occurring problems. All had limitations in their design, implementation and delivery. These limitations can be summarised as:

- The authoring toolkit was no longer supported. VR authoring toolkits have frequently become obsolete as manufacturers go out of existence, or change their market

- VR was not necessarily the best technology for achieving the learning objectives and other technologies would be more suitable and effective.

- Implementation was not robust enough as the software had been developed for an educational market by research programmers without experience of systematic functional and acceptance testing

- The software was inflexible and expensive to produce incurring high production costs to produce learning environments that remained fixed and difficult and expensive to reconfigure.

- There was not enough or appropriate learning support embedded in the software

- The requirements of the users were not entirely appreciated at the design stage. 
Most of these issues were easier to avoid once our team had accumulated more experience. For example, we embarked on studies on embedded learning support and employed user sensitive inclusive design methods and these are dealt with in subsequent sections. Continual evaluation of the VE we develop has aided the definition of an emergent set of design guidelines (Table 1). These are by no means complete and have not been applied to enough alternative applications to establish their generalisability. However, they provide a useful starting point for those designing specifically for people with intellectual disabilities.

\section{Providing support for learning}

The dangers of unguided use of VE have already been referred to above when the role of the human tutor was discussed. An additional method to guide interaction and thus facilitate learning would be to incorporate some of the functions traditionally ascribed to the human tutor into the software ${ }^{40}$. This would be either in the form of unintrusive tutoring (giving advice but not preventing actions) or intelligent software tutoring (providing feedback based on the tutoring agent's experience of the task and the learner's behaviour).

In order to collect information to inform the design of software tutors, we observed what strategies human tutors used when working with adults who were learning to use virtual environments and how effective these strategies were ${ }^{41}$. Data were collected on 20 people attending a social services day service for people with severe intellectual disabilities while they worked through four VE: road crossing, café, supermarket and factory, all of which presented the learner with a series of tasks (for example, ordering and paying for drinks in the café). Learners used the joystick to move around the environments and a standard two-button mouse to interact with them. Each participant spent a session using a two-dimensional routine to learn how to use the mouse. Once this had been mastered they moved on to the other environments in the same order, only progressing to the next once a defined level of mastery had been achieved. Sessions were scheduled to twice a week and lasted approximately 30 minutes. They were recorded on videotape, the camera positioned to view both the tutor and the learner sitting next to them. 
The teachers' behaviour was categorised as giving information, giving feedback or praise ("that's right"), using gestures or helping with the controls. Information was further categorised as specific ie it was instrumental in achieving a goal (for example, 'Go over to the bar now.') or non-specific. This referred to information that did not provide the help that a learner needed to achieve a goal, but made the learner aware of possibilities (for example, 'Where are you going to go now?’). The behaviour of the learner was categorised in terms of the number of goals they achieved in an environment for example, finding an item on the shopping list.

Although learners achieved approximately the same number of goals during each session, as in our earlier study ${ }^{38}$ tutors' contributions to each session varied between earlier and later sessions. In the early sessions, tutors provided much more specific information and gestures. This suggests that, in order for the learner to achieve goals in early sessions, the tutor needed to give more directive or controlling instructions. Levels of non-specific information remained high throughout all sessions. So in spite of having to give more specific information in early sessions, tutors still found opportunities to maintain the learner's engagement and to put their activity into a broader context.

The distinction between 'specific' and 'non-specific' information follows work on children's learning ${ }^{39}$ which highlighted the different levels of control a teacher might have over a pupil. The changes in tutor behaviour during the study described above suggest that this distinction is worth maintaining. The tutors appeared to be following the expected pattern of intervening or controlling less and less. In turn, this allowed more time for the tutor behaviours that maintain the learner's interest and motivation and which help to interpret the learner's activity. Giving less specific information did not cause the learner to make more errors, which supports the judgement of the tutor in reducing their prompts.

The distinction between levels of tutor control might also correspond to that which can be written into virtual reality software as distinct from those that need the presence of a human tutor. For example, specific information and feedback could be written into the software. Similarly, gesturing was largely used by teachers either to 
draw the learner's attention back to the screen, or to draw their attention to a salient feature. The latter function could be incorporated into software by making a particular feature more prominent.

While such modifications could not provide all the functions of a human tutor, they would allow the human tutor to concentrate on other aspects of the tutor role. For example the human tutor could valuably provide the non-specific information that maintains the learner's interest and motivation. They might also allow for the possibility of a peer acting as a tutor. In mainstream education co-operative learning and peer tutoring have been investigated as a cost-effective deployment of teacher time. This might free the teacher from the stress of monitoring a large group and leave additional time for the more complex instruction that only a human being can provide. A review ${ }^{42}$ showed that peer interaction can support the learning of both specific and general skills. Advantages are that the learner might experience more practice through staying on the task for greater proportions of contact time. They might also enjoy the companionship, possibly responding on a personal level better to peers than to a teacher. Peer tutoring has had limited use in special-needs education. With careful matching of the peer, the learner and the task more could perhaps be done in this area in future.

The findings from this study were used to design an environment to teach travel training skills to young people with intellectual disabilities so that they may have greater independence and access work-based, learning and other social activities ${ }^{43}$. It depicts several scenarios where one might cross the road: for example, where there is no designated crossing place, at a pedestrian controlled crossing and at a road junction. Level of traffic density and the presence of parked cars can be varied in order to provide virtual environments which give an increased level of difficulty as the learner progresses. For each version of the software, two forms exist: one with a virtual tutor, and one without. The virtual tutor provides information by visually highlighting the crossing route and by giving audible feedback (either verbal or nonverbal) when the learner achieves a goal or makes an error, for example by stepping into the road outside a designated crossing area. The next stage would be to develop an intelligent tutor that adjusts to take account of the learner's previous patterns of achievements and mistakes in the environment. 


\section{Involving teachers and students in design of software and devices}

The only way to produce appropriate educational virtual environments that meet relevant educational aims and are easy and motivating to use is to involve users in their design. Users in this case are both the students and those who support their learning. Guidelines exist for a user sensitive inclusive design ${ }^{44}$ and also standards for Software Product Quality ${ }^{45}$ and Human-centred Lifecycle Process Descriptions ${ }^{46}$. Current developments of both software and hardware have utilised this approach ${ }^{43}, 47$,

${ }^{48}$ with students with intellectual and multiple disabilities and it allows the involvement of users at each stage of development. This approach involves the setting up of a usability group which comprises users as well as relevant experts and practitioners and a user group which comprises individuals who are representative of the intended users of the product who may stay with the project for its entire history or who may join for only part of it. Users are selected to represent the range of relevant characteristics eg age, sex, ability, presence of additional diagnoses and these characteristics and abilities of the user group are collected and recorded before their involvement in the project. Before any prototypes are developed, a thorough analysis is made not only of the users' abilities but also of the task and the environment to produce a comprehensive Requirements Specification $^{49}$.

\section{Problems with input devices}

The work carried out so far has employed desktop VR where the environment is displayed on an ordinary computer monitor. Utilising control devices, the user's tasks are to navigate their way around the environment and interact with it. Primary navigation (ie finding one's way in the environment can be on a continuum between automatic, where the user is taken through the environment without any action on their part and self-controlled. In reality it is usually semi automatic, i.e. constrained by the software. So, for example, many environments employ terrain tracking where the user can only move on a horizontal plane. Within this plane there are usually 2 degrees of freedom, i.e. forward /back, turning left or right. Interaction can activate 
objects (select item on supermarket shelf and move it into trolley), move them or cause one object to interact with another (eg put a key in the lock).

A variety of devices are employed for controlling the software but for navigation a joystick limited to two degrees of freedom was recommended as having the greatest utility $^{50}$. The more functions a device possesses, the more difficult it is to operate. So, for example, when using a spaceball which has six degrees of freedom, the user with intellectual disabilities frequently became lost. An evaluation of a range of affordable and robust interaction and navigation devices, also favoured use of the joystick finding it more suitable for navigation tasks than the keyboard. For interaction tasks, if drag-and-drop was not required, the touch-screen and mouse were equally effective, although the touch-screen was difficult to calibrate ${ }^{51}$. The more recently developed hands free devices for people with neuromuscular difficulties are designed to replace control of the cursor and so have limited application for use in virtual environments. They are based on reflecting light from part of the body, for example with a light reflecting dot stuck onto the forehead, which is then picked up by an infra red camera mounted on the computer. People with intellectual disabilities take a long time to understand the connection between movement of their head and movement of the cursor and many dislike having things stuck on their body especially their head and try to remove the object.

However, even the preferred devices of joystick for navigation and two button mouse for interaction are not without their problems. The two main reasons for this are the level of cognitive ability of the users and motor difficulties they experience. In the study described above ${ }^{41}$ much of the time spent by the tutor in the learner's early sessions was on providing assistance with the input devices. Users experienced problems in remembering what tasks were accomplished by each device and in moving from one device to the other as many used the same (dominant) hand for both devices. Many people with intellectual disabilities have fine motor difficulties as they suffer from conditions where damage has been caused to the central nervous system, such as cerebral palsy, multiple sclerosis, muscular dystrophy and dyspraxia. They therefore find the devices difficult to control. A detailed analysis was carried out ${ }^{52}$ of the difficulties experienced by fourteen school aged students with intellectual disabilities using a joystick for navigation and a mouse for interaction to complete 
specified navigation and interaction tasks within the virtual city ${ }^{53}$. Many of the difficulties users experienced were due to physical ability and device construction. Finally, difficulties arose as a result of the design of the VE. With problems like these, users can become frustrated and demotivated. Using a methodology established in an earlier study ${ }^{41}$, we set out to systematically document the performance of users with the currently recommended devices (standard 3 axis games joystick; standard two button mouse and keyboard) ${ }^{54}$. The intention was to collect information which could then be used to inform the design of a usable control device or devices and to act as a baseline against which they can be evaluated.

Forty people who regularly attended a day centre for people with intellectual disabilities volunteered to take part. They were selected to represent a wide range of age, motor and cognitive ability. Four training VE were constructed in order to evaluate the currently used devices as well as any prototypes that were developed. In order to increase their attractiveness to users and facilitate the acquisition of navigation and interaction skills they were all designed using game format in that they consisted of varying levels of difficulty with access to each level only allowed once the correct level of performance had been achieved at the previous level. Additionally, feedback in the form of scores was available to the user. Each environment constrained different possibilities in order to test a range of uses of the control devices but without presenting the user with too many options initially. For example, some environments provided forward movement by applying a constant linear velocity to the z-axis (horizontal plane/forward) of an avatar which was positioned just in front of the user's position within the environment. This adaptation left the user with the task of moving in only the x-axis (left/right) and y-axis (up/down). The software also collected information on task achievement (scores), time taken and collisions. As in all our previous studies, one of the researchers sat alongside the participant to give assistance and encouragement. Each session was recorded on videotape and their analysis yielded measures of help given by the researcher. This was described as concerning the devices (whether for navigation or interaction) or the environment and was also categorised according to whether it was verbal (information) or physical (giving assistance). 
Results indicated that the real challenge for the participants was when they had to effect forward movement as this could only be achieved with either the joystick or the arrows on the keyboard. Using both of these required considerable help from the researcher especially as many participants exerted too much force on the joystick and the researcher had to hold on to its base to prevent it slipping. Apart from slipping the joystick required less information and assistance than did the keyboard and enabled participants to gain consistently higher scores. Most participants had no problem using the mouse but this only allowed cursor control and interaction. Use of the joystick could be avoided by writing forward movement into the software and for some tasks in a VE this would not be appropriate but it would be informative to explore this option further. When navigation is required in a three dimensional environment the joystick once mastered does allow even some of the most disabled users to achieve better performance. These results suggest that resolving some of the physical difficulties with the joystick may reduce the likelihood of demotivation on initial usage and also allow better performance once use of the device has been mastered.

A review of the results suggested two possible design solutions: to modify the joystick as it allows better performance but takes time to master and secondly to devise a two handed device. This second solution had arisen from work with a prototype two handed device that combined both navigation and interaction. This study had found that users were confused about which action caused interaction, which navigation ${ }^{55}$. We therefore decided to retain the mouse for interaction and find a design solution purely for navigation. Repeating the baseline tests indicated that a wheel-shaped two handed device was not as good as the modified joystick which had no redundant buttons and was fitted with a sticky base to prevent slipping and a plate to limit movement in unintentional directions. Of all these modifications, the addition of a sticky base produced the greatest improvement in outcome measures. One advantage of this modification appears to be that it allows the user to improve their performance through giving them more accurate feedback on how much force to exert. 


\section{Ethical issues}

In our 1996 paper $^{4}$ we considered ethical issues that may arise from the use of VR with people with intellectual disabilities. Many of the fears about VR arose from unrealistic notions of what the technology could actually make possible ${ }^{56}$. We speculated that many of the ethical issues raised might recede once potential users understood exactly what VR was and what it could achieve. Are these ethical issues still pertinent and have new ones joined them?

One of the early fears was that vulnerable users would fail to distinguish between the virtual and the real world. With the development of increasingly complex graphic cards, the proliferation of high speed and affordable processors and increasingly subtle rendering techniques there seems even more justification for this fear. Writing about those with mental disorders but also pertinent for those with intellectual disability, Whalley ${ }^{57}$ stated that VR may have the capacity to distort reality testing in those for whom it is already impaired. Getting hit by a virtual car cannot convey exactly what happens when getting hit by a real car so would the virtual experience convey unrealistic expectations of the real one? This is a possibility with all methods of training for a potentially risky skill that involves protecting the learner from severe risks and this is where the involvement of a tutor becomes crucial. Their role in “interpreting the learner's activity"39 would help the learner make the connection and appreciate the distinctions between the real world and the model of it with which they are working.

Another fear was the lack of social contact that may result from learning via a computer especially for a group who experience a greater degree of social isolation than most and that time spent in VR would reduce the time available to learn social skills for those who already had an impaired ability to negotiate their place within the socially shared physical world ${ }^{57}$. These fears arose from an expectation that VR would replace conventional teaching in such a way that students would experience reduced contact with a tutor. Our work has shown that this is not necessarily the best way to proceed but both use of immersive and non-immersive systems needs to be embedded in a curriculum where the social dimension of learning is given high priority. Preliminary work with young people with autistic spectrum disorders has 
even suggested that VR might have a beneficial effect on the acquisition of social skills by teaching the rules on which social interactions are based ${ }^{58}$. Other benefits proposed for playing computer games ${ }^{59}$ could also be found with VR. For example, a randomised control trial ${ }^{60}$ found a reduction in choice reaction time in a group who used an educational VR.

Other ethical issues are still prominent, for example raising the expectations of potential users and encouraging them to invest in expensive systems that fail to deliver. However, ethical issues should be part of the dialogue between users and developers that is facilitated by user sensitive inclusive design.

\section{Future developments}

For people with intellectual disabilities more so than the general population, education continues well after school leaving age. Consequently the development of educational VR must also take account of their training needs ${ }^{22}$. Much of our work is carried out with adult day centre attenders or young people in supported employment, designing software to fill this gap. The game format we used in the study of input devices is something we exploit in much of the educational software we produce and works well whatever the age group as long as the content is age appropriate. Obtaining learning materials suitable for older people with intellectual disabilities is challenging: using those designed for non-disabled children is quite often demeaning and unlikely to engage their interest. However, there are also other groups who might benefit from this technology but whose needs are currently not met by the current generation of VR. One such group is students with visual impairments. While those with some residual vision can be catered for through manipulating the visual display and.allowing the user to zoom in on objects, most programmes are not suitable for those those with extremely limited visual ability. For this group it is possible to develop acoustic virtual environments ${ }^{61}$ but such developments are few and we know little about how to construct such environments in order to assist the visually impaired to navigate through them.

The current technology also excludes those who are so profoundly disabled that they have a limited understanding of three dimensional space. However, this group can 
benefit from two dimensional interactive software interfaced by a switching device ${ }^{62}$ and from Aesthetic Resonant Environments ${ }^{63}$ where data from the user's body, for example movement or breath pressure,are captured by sensors or cameras to drive multimedia displays tailored to the particular user's interests.

While desktop systems continue to be the cheapest and most available route for delivering VE, the possibility of exploiting new technological developments needs to be considered. Earlier immersive applications were not suitable for people with intellectual disabilities but newer systems with an almost undetectable time lag should be explored as they have distinct advantages in the navigation of new environments by providing a wider field of vision. Whether using immersive or non-immersive systems, wireless interfaces would facilitate the use of VR by those with multiple physical disabilities. However, future work should focus on the development of an intelligent interface that takes account of changes in the user's behaviour either in terms of increasing ability with familiarity or the unfortunate but inevitable decline in ability that comes with ageing or with some degenerative neurological conditions.

Finally, with the realisation that VR has a role to play in the cognitive rehabilitation of people with intellectual disabilities ${ }^{63}$ there is the potential to develop systems that simultaneously assess and address the educational, rehabilitative and therapeutic needs of a group who could greatly benefit from these advances in technology.

\section{References}

1. Sherman B (1992) Birth of a brave new world. Computers March: 3-4

2. Rizzo A (2002) Virtual reality and disability: emergence and challenge. Disability and Rehabilitation 24 (11-12): 567-569

3. Barry PL, Phillips (2002) Whatever happened to virtual reality? http://www.firstscience.com/site/articles/virtual_reality.asp

4. Cromby JJ, Standen PJ, Brown DJ (1996) The potentials of virtual environments in the education and training of people with learning disabilities. Journal of Intellectual Disability Research 40(6): 489-501

5. Busby G (2005) Making a connection: Social Inclusion and Disability. IT Now: The magazine for the IT Professional July: 6-7

6. Goldenberg E P (1979) Special Technology for Special Children. University Park Press: Baltimore, MA.

7. Dube WV, Moniz DH, Gomes JF (1995) Use of computer- and teacher delivered prompts in discrimination training with individuals who have mental retardation. American Journal on Retardation 100: $253-261$ 
8. Chen SHA, Bernard-Opitz V (1993) Comparison of personal and computer-assisted instruction for children with autism. Mental Retardation 31: 368-376

9. Hawkridge D, Vincent T (1992) Learning Difficulties and Computers. Jessica Kingsley: London

10. Blamires M (Ed) (1999) Enabling Technology for Inclusion. London: Paul Chapman Publishing

11. Pantelidis VS (1993) Virtual reality in the classroom. Educational Technology April: 23-27

12. Sims D (1994) Multimedia camp empowers disabled kids. IEEE Computer Graphics and Applications January 1:14-15

13. Salem-Darrow M (1996) Virtual reality’s increasing potential for meeting needs of person with disabilities: what about cognitive impairments? In: Proceedings of the Third International Conference on Virtual Reality and Persons with Disabilities. Murphy HJ ed. California State University Center on Disabilities: C A Northridge

14. Shakespeare R (1975) The Psychology of Handicap. Methuen, London.

15. Middleton T (1992) Advanced technology for enhancing the education of students with disabilities. Journal of Microcomputer Applications January: 1-7

16. McLellan H (1991) Virtual environments and situated learning. Multimedia Review 2: 30-37

17. Bricken W (1991) Training in virtual reality. In: Proceedings of the 1st International Conference on Virtual Reality. Meckler International: London

18. Donaldson M (1978) Children’s Minds. Fontana: London

19. Vygotsky LS (1978) Mind in Society: The development of higher psychological processes. Harvard University Press: Cambridge, Mass

20. Bruner JS (1968) Processes of Cognitive Growth: Infancy. Clark University Press: USA

21. Department of Health (2001) Valuing People: a new strategy for learning disability for the $21^{\text {st }}$ century. London: HMSO

22. Tomlinson J (1997) Inclusive learning: the report of the committee of enquiry into the post-school education of those with learning difficulties and/or disabilities in England 1996. European Journal of Special Needs Education 12 (3): 184-196

23. National Development Group for the Mentally Handicapped (1977) Day Services for Mentally Handicapped Adults. Department of Health and Social Security: London

24. Gow LP, Balla J, Butterfield E (1990) The relative efficacy of cognitive and behavioural approaches to instruction in promoting adaptive capacity. In: Key Issues in Mental Retardation Research. Fraser WI ed. Routledge: London UK 366-376

25. Robertson I, Richardson AM, Youngson SC (1984) Social skills training with mentally handicapped people: a review. British Journal of Clinical Psychology 23: 241-264

26. Davies RR, Rogers ES (1985) Social skills training with persons who are mentally retarded. Mental Retardation 23: 186-196

27. Stokes TF, Baer D (1977) An implicit technology of generalisation. Journal of Applied Behaviour Analysis 10: 349-367

28. Ward J, Gow LP (1982) Programming generalisation: a central problem area in clinical psychology. Educational Psychology 2: 231-248

29. Selman RL, Jaquette D (1977) Stability and oscillation in interpersonal awareness: a clinicaldevelopmental analysis. In: Nebraska Symposium on Motivation Keasey CB ed. 25: 261-304

30. Baty FJ, Michie MA, Lindsay WR (1989) Teaching mentally handicapped adults to use a cafeteria. Journal of Mental Deficiency Research 33: 137-148

31. Standen PJ, Cromby JJ, Brown DJ (1998) Playing for real. Mental Health Care 1: 412-415 
32. Light, P (1997) Annotation: Computers for learning: psychological perspectives. Journal of Child Psychology and Psychiatry 38: 497-504

33. Salem Darrow, M (1995) Increasing research and development of virtual reality in education and special education: what about mental retardation? VR in the Schools 1 (3): 1-7

34. Rostron, A Sewell, D (1984) Microtechnology and Special Education. Croom Helm: London

35. Nemire K, Crane R (1996) Designing a virtual science laboratory to accommodate needs of students with cerebral palsy. In: Proceedings of the Tenth International Conference on Technology and Persons with Disabilities. Murphy HJ ed. California State University Center on Disabilities: Northridge, CA

36. Mayer RE (2004) Should there be a three-strikes rule against pure discovery learning? American Psychologist 59 (1): 14-19

37. Rutkowska JC, Crook C (1987) Computers, Cognition and Development. Wiley: Chichester

38. Standen PJ, Low HL (1996) Do virtual environments promote self-directed activity? A study of students with severe learning difficulties learning Makaton Sign language. In: Proceedings of the First European Conference on Disability, Virtual Reality and Associated Technologies. Sharkey PM ed. Maidenhead, UK 123-127

39. Wood D, Bruner JS, Ross G (1976) The role of tutoring in problem solving. Journal of Child Psychology and Psychiatry 17: 89-100

40. Slator B M, Juell P, McClean P E, Saini-Eidukat B, Schwert D P, White A R, Hill C (1999), Virtual environments for education at NDSU. World Conference on Educational Media, Hypermedia and Telecommunications (ED-MEDIA 99). 19-24 June, Seattle, WA: 875-880

41. Standen PJ, Brown DJ, Proctor T, Horan M (2002) How tutors assist adults with learning disabilities to use virtual environments. Disability and Rehabilitation 24 (11-12): 570-577

42. Topping K. (1992) Co-operative learning and peer tutoring: An overview. The Psychologist 5: 151-161

43. Shopland N, Lewis J, Brown DJ, Dattani-Pitt K (2004) Design and Evaluation of a flexible travel training environment for use in a supported employment setting. Proceedings of the Fifth International Conference on Disability, Virtual Reality and Associated Technologies Sharkey PM ed. 69-76

44. Buchenau M, Suri JF (2000) Experience prototyping. Symposium on Designing Interactive Systems. Proceedings of the ACM conference on Designing interactive systems: processed, practices, methods, and techniques. August 17 - 19, 2000, Brooklyn, NY United States.

45. ISO/IEC. 9126 Software Product Quality - Quality Model. ISO/IEC 9126: 2000 (E)

46. ISO/IEC. 18529 Human-centred Lifecycle Process Descriptions. ISO/IEC TR 18529: 2000 (E)

47. Standen PJ, Brown DJ, Anderton N, Battersby S (2004) A systematic evaluation of problems with control devices experienced by people with intellectual disabilities using virtual environments. Proceedings of the Fifth International Conference on Disability, Virtual Reality and Associated Technologies Sharkey PM ed. 299-304

48. Battersby S, Brown DJ, Standen PJ, Anderton N, Harrison M (2004) Design, development and manufacture of novel assistive /adaptive technology devices for virtual learning environments. Proceedings of the Fifth International Conference on Disability, Virtual Reality and Associated Technologies Sharkey PM ed. 283-290

49. Poulson DF, Waddell FN (2001) USERfit: User centred design in assistive technology. In: Inclusive guidelines for HCI. Nicholle CA, Abascal J eds. Tailor and Francis

50. Hall JD (1993) Explorations of Population Expectations and Stereotypes with Relevance to Design undergraduate thesis, Department of Manufacturing Engineering, University of Nottingham

51. Brown DJ, Kerr SJ, Crosier J (1997) Appropriate input devices for students with learning and motor skills difficulties. Report to the National Council for Educational Technology: UK 
52. Lannen TJ, Brown DJ, Powell H (2002) Control of virtual environments for young people with learning difficulties. Disability and Rehabilitation 24 (11-12): 578-586

53. Brown DJ, Neale H, Cobb SV, Reynolds H(1999) The development and evaluation of the virtual city. International Journal of Virtual Reality 4 (1): 28-41

54. Standen PJ, Brown DJ, Anderton N, Battersby S (2004) A systematic evaluation of problems with control devices experienced by people with intellectual disabilities using virtual environments. Proceedings of the Fifth International Conference on Disability, Virtual Reality and Associated Technologies Sharkey PM ed. 299-304

55. Lannen TJ (2002) A multi-disciplinary approach to the control of virtual environments for young people with moderate to severe learning difficulties. PhD thesis, Nottingham Trent University.

56. Whitbeck C (1993) Virtual environments: ethical issues and significant confusions. Presence 2: 147-152

57. Whalley LJ (1993) Ethical issues in the application of virtual reality to the treatment of mental disorders. In: Virtual Reality Systems. Earnshaw RA, Gigante MA, Jones H eds. 273-287 Academic Press: London

58. Parsons S, Mitchell P (2002) The potential of virtual reality in social skills training for people with autistic spectrum disorders. Journal of Intellectual Disability Research 46 (5): 430-443

59. Griffiths M (2004) Can videogames be good for your health? Journal of Health Psychology 9 (3): 339344

60. Standen PJ, Ip WMD. (2002) An evaluation of the use of virtual environments in improving choice reaction time in people with severe intellectual disabilities. In: Proceedings of the Fourth International Conference on Disability, Virtual Reality and Associated Technologies. Sharkey PM, Sik Lányi C, Standen PJ, eds. 19-24

61. Lahav O, Mioduser D (2000) Multisensory virtual environment for supporting blind persons' acquisition of spatial cognitive mapping, orientation and mobility skills. In: Proceedings of the Third International Conference on Disability, Virtual Reality and Associated Technologies. Sharkey PM, Cesarani A, Pugnetti L, Rizzo A, eds. 53-58.

62. Anderton N, Standen PJ, Avory K (2004) Using switch controlled software with people with profound disabilities. In: Proceedings of the Fifth International Conference on Disability, Virtual Reality and Associated Technologies. Sharkey PM, McCrindle R, Brown D, eds. 269-274.

63. Brooks T., Camurri A, Canagarajah N, Hasselblad S (2002) Interaction with shapes and sounds as a therapy for special needs and rehabilitation. . In: Proceedings of the Fourth International Conference on Disability, Virtual Reality and Associated Technologies. Sharkey PM, Sik Lányi C, Standen PJ, eds. 205-212

64. Standen PJ, Brown DJ (2005) The use of virtual reality in the rehabilitation of people with intellectual disabilities. Cyberpsychology and Behaviour 8 (3): 272 - 282 


\begin{tabular}{|c|c|}
\hline Issue & Guideline \\
\hline Communication & $\begin{array}{l}\text { - Instructions should be atomic in order for the user to } \\
\text { easily remember them. } \\
\text { - When the user is required to listen to instructions or } \\
\text { learning objectives, any further interaction should be } \\
\text { prevented until after this has terminated. } \\
\text { - The use of text should be avoided. Alternatives should } \\
\text { include pictorial representations such as icons or Makaton } \\
\text { symbols. This should also be combined with a voice-over. } \\
\text { - Speech therapists should be consulted to simplify text and } \\
\text { suggest symbols. }\end{array}$ \\
\hline Navigation & $\begin{array}{l}\text { Doorways should be wider than they are in reality to } \\
\text { reduce the problems that are encountered when } \\
\text { approaching them from an angle. } \\
\text { - When there is a need to position a viewpoint or an item, } \\
\text { allow for extra tolerance. }\end{array}$ \\
\hline Interaction & $\begin{array}{l}\text { - Avoid the need to use more than one button of the input } \\
\text { device. The use of the mouse should be restricted to the } \\
\text { left button only. } \\
\text { - Events requiring complicated input device actions can be } \\
\text { useful for learning computer skills but should not be an } \\
\text { integral part of the main program. } \\
\text { - The input devices to be used should, wherever possible, } \\
\text { ensure maximum accessibility for the disabled } \\
\text { community. } \\
\text { - If an object is small, the "clickable" area should be larger } \\
\text { than the object. } \\
\text { If the user is prompted to click an object, it should be } \\
\text { visible at the time of the prompt. } \\
\text { Wherever possible, an action should require only a single } \\
\text { click of the input device. }\end{array}$ \\
\hline
\end{tabular}




\begin{tabular}{|l|l|}
\hline Learning support & $\begin{array}{l}\text { If the user is required to select items in order and they } \\
\text { select the wrong order, they should receive prompts to } \\
\text { reiterate the correct order. } \\
\bullet\end{array}$ \\
The use of icons and pictorial prompts should be \\
consistent and standardized (that is, green for yes, red for \\
no) throughout the whole of the software. \\
Dialogue boxes should remain on screen for a length of \\
time that is appropriate for the ability of the user. \\
The VLE should contain as many real-life cues as \\
possible so long as they don't distract the user from the \\
learning objective. \\
To allow for the difference in abilities, users should be \\
able to bypass advanced learning objectives. \\
Ethics
\end{tabular}

